\title{
Le Brésil d'André Thevet. "Les Singularités de la France Antarctique" (1557), édition intégrale établie, présentée et annotée par Frank Lestringant
}

\section{Michele Mastroianni}

\section{(2) OpenEdition Journals \\ Edizione digitale \\ URL: https://journals.openedition.org/studifrancesi/4647 \\ DOI: $10.4000 /$ studifrancesi.4647 \\ ISSN: 2421-5856 \\ Editore \\ Rosenberg \& Sellier}

\section{Edizione cartacea}

Data di pubblicazione: 1 avril 2012

Paginazione: 135

ISSN: 0039-2944

\section{Notizia bibliografica digitale}

Michele Mastroianni, «Le Brésil d’André Thevet. "Les Singularités de la France Antarctique" (1557), édition intégrale établie, présentée et annotée par Frank Lestringant», Studi Francesi [Online], 166 (I | LVI) |

2012, online dal 30 novembre 2015, consultato il 19 novembre 2021. URL: http://

journals.openedition.org/studifrancesi/4647 ; DOI: https://doi.org/10.4000/studifrancesi.4647

Questo documento è stato generato automaticamente il 19 novembre 2021.

\section{c) (†) $\odot$}

Studi Francesi è distribuita con Licenza Creative Commons Attribuzione - Non commerciale - Non opere derivate 4.0 Internazionale. 


\title{
Le Brésil d'André Thevet. "Les
}

\section{Singularités de la France Antarctique" (1557), édition intégrale établie, présentée et annotée par Frank Lestringant}

\author{
Michele Mastroianni
}

\section{NOTIZIA}

Le Brésil d'André Thevet. "Les Singularités de la France Antarctique" (1557), édition intégrale établie, présentée et annotée par Frank LESTRINGANT, Paris, Éditions Chandeigne, 2011, pp. 567.

1 Continuando le sue infaticabili ricerche sulla letteratura di viaggio (in particolare cinquecentesca), che lo hanno portato a studiare e pubblicare testi sul Nouveau Monde che hanno un indubbio valore per la disciplina e la storia dell'etnografia, oltre che per lo studio della mitografia letteraria (oggetto prediletto di tali indagini sono le opere di Jean de Léry e di André Thevet), Frank Lestringant pubblica ora, in formato maneggevole, l'edizione integrale delle Singularités de la France Antarctique, autrement nommée Amérique (1557), opera contemporanea della spedizione in Brasile di Nicolas Durand de Villegagnon (1555-1560). In essa abbiamo la repertoriazione della flora e della fauna del Nuovo Mondo, la descrizione delle fasi più violente del rituale antropofago, un rapporto sulle più piccole attività della società Tupinamba. Il libro è consacrato in parte agli Indios cannibali della baia di Rio de Janeiro, in parte agli Irochesi della valle del Saint-Laurent: esso inaugura una tradizione che passando per Montaigne e per autori del Seicento culmina, all'epoca dei Lumi, nel mito del «buon selvaggio», caro all'abbé Raynal. Definita «fenêtre sur le Nouveau Monde» quest'opera è 
in realtà risultato di una costruzione erudita, e soprattutto non è di prima mano, in quanto Thevet soggiornò pochissimo in Brasile e vi fu quasi sempre ammalato: pertanto si giovò sia delle informazioni raccolte da residenti di lunga data sia della collaborazione di un ellenista, per poter offrire una descrizione della cultura degli Indios con in filigrana tutti quei riferimenti a Omero, Virgilio, Ovidio o Plutarco richiesti dalla sensibilità dell'uomo colto del Rinascimento. Racconto di viaggio, la relazione di Thevet descrive anche le curiosità dei paesi (d'Africa e d'America) toccati nel percorso di andata e ritorno. L'introduzione di F. Lestringant situa il testo nel quadro della fortuna francese cinquecentesca della letteratura americanista e, soprattutto, offre una ricostruzione precisa dei rapporti culturali intrecciati da Thevet, sia a livello di interessi che potremmo definire etnologici sia in un quadro più ampio di interessi politici e religiosi. Acute le considerazioni sull'approccio antropologico, che prelude, come si è detto, a una precisa filière letteraria. Pubblicata originariamente nella «Magellane», nel 1997, questa edizione delle Singularités, ricompare con un testo accuratamente revisionato e le note arricchite e completate sulla base della bibliografia più recente. L'edizione è particolarmente interessante e utile anche per il fatto di riprodurre la ricca messe di tavole della stampa cinquecentesca. 